Revista Destaques Acadêmicos, Lajeado, v. 8, n. 4, 2016. ISSN 2176-3070 DOI: http://dx.doi.org/10.22410/issn.2176-3070.v8i4a2016.1045 www.univates.br/revistas

\title{
AVALIAÇÃO DA DEGRADAÇÃO DA CAFEÍNA EM AMOSTRAS DE ÁGUA USANDO ESPECTROFOTOMETRIA APÓS TRATAMENTO COM PROCESSOS OXIDATIVOS AVANÇADOS
}

\author{
Joseane Parizzi Mafioleti ${ }^{1}$, Rosecler Ribeiro ${ }^{2}$, Daniel Kuhn ${ }^{3}$, Simone Stulp ${ }^{4}$, \\ Lucélia Hoehne ${ }^{5}$
}

Resumo: As técnicas convencionais de tratamento de água se mostram ineficientes na remoção de contaminantes conhecidos como micropoluentes emergentes que são associados principalmente ao esgoto doméstico. Estes micropoluentes são classificados como fármacos, produtos de cuidado pessoal e desreguladores endócrinos e são substâncias que causam efeitos adversos ao meio ambiente e a saúde pública. A cafeína é incluída no grupo dos fármacos, muito utilizado em alimentos, bebidas e condimentos e se mostra como um indicador potencial de contaminação de águas por esgoto doméstico. A proposta para o tratamento destes micropoluentes emergentes são os processos oxidativos avançados (POAs), os quais utilizam técnicas de oxidação química que geram radicais hidroxilas extremamente reativos que transformam estas substâncias indesejáveis em outras menos tóxicas. No presente trabalho foi avaliada a degradação da cafeína em amostras de águas, após a aplicação de processos oxidativos avançados fenton, foto-fenton e fotólise de peróxido de hidrogênio. Para realização dos experimentos de foto-fenton e fotocatálise de peróxido de hidrogênio foi utilizado o planejamento fatorial 23 tendo como variáveis a concentração de ferro, peróxido de hidrogênio e o tempo de exposição à radiação UV. Para testes do processo fenton

1 Bacharel em Engenharia Ambiental pelo Centro Universitário UNIVATES, Lajeado/RS. joseane.parizzi@gmail.com

2 Bacharel em Química Industrial pelo Centro Universitário UNIVATES, Lajeado/RS. roseclerr@universo.univates.br

3 Bacharel em Química Industrial pelo Centro Universitário UNIVATES, Lajeado/RS. danielkuhn@universo.univates.br

4 Professora do Centro Universitário UNIVATES, PPG em Ambiente de Desenvolvimento, Lajeado/RS. Doutora em Química. stulp@univates.br

5 Professora do Centro Universitário UNIVATES, PPG em Biotecnologia, Lajeado/RS. Doutora em Química. luceliah@univates.br 
foram simuladas duas situações variando as concentrações de ferro e peróxido de hidrogênio. Após a aplicação dos testes com POAs, foi avaliada a melhor condição de tratamento, que foi a fotólise de peróxido de hidrogênio utilizando $68 \mathrm{mg} / \mathrm{L}$ de peróxido de hidrogênio e 5 minutos de exposição a radiação UV, que resultou em 100\% de degradação da cafeína.

Palavras-chave: Cafeína. Processos oxidativos avançados. Planejamento fatorial. Qualidade das águas

\section{INTRODUÇÃO}

O crescimento populacional tem sido a maior fonte de poluição dos corpos d'água, pois com ele trazem o aumento da ocupação urbana e das atividades industriais, agrícolas e pecuárias, causando impactos quanto a geração de esgoto doméstico, resíduos e contaminantes e uso de pesticidas e fertilizantes (LIBÂNIO, 2008).

Recentemente, estudos aliados a substâncias químicas chamadas de micropoluentes emergentes vem sendo desenvolvidos, pois são associados aos esgotos, tratados ou não, que chegam as águas superficiais e causam efeitos adversos ao meio ambiente e à saúde pública (SANTANA, 2013).

São considerados micropoluentes emergentes fármacos, produtos de cuidado pessoal e desreguladores endócrinos. No grupo dos fármacos encontrase a cafeína, que além de ser utilizada em medicamentos é amplamente consumida em alimentos, bebidas e condimentos (SOUZA, 2011). A presença de cafeína em águas superficiais e subterrâneas é de origem antrópica, pois esta não é consumida por animais e nem está presente em fertilizantes, assim é considerada um indicador de contaminação por esgotos domésticos (TUBBS; FREIRE; YOSHINAGA, 2004).

Estudos para remoção destas substâncias têm sido feitos acerca de processos oxidativos avançados (POAs), os quais utilizam técnicas de oxidação química que geram radicais hidroxilas extremamente reativos que transformam estas substâncias indesejáveis em outras menos tóxicas (DALMÁZIO, 2007). Dentre os mais utilizados estão a fotólise de peróxido de hidrogênio de peróxido de hidrogênio, que utiliza peróxido de hidrogênio e radiação ultravioleta (UV), processo Fenton, que utiliza compostos de ferro e peróxido de hidrogênio e foto-fenton, que se trata do processo Fenton com radiação UV.

Dentro desta problemática, foi proposta a aplicação dos processos oxidativos avançados Fenton, fotólise de peróxido de hidrogênio de peróxido de hidrogênio e foto-fenton para o tratamento do micropoluente cafeína, utilizando planejamento fatorial $2^{3}$ para os experimentos de fotólise de peróxido de hidrogênio e foto- Fenton que terão como variáveis a concentração de ferro, peróxido de hidrogênio e o tempo de exposição à radiação UV e mantendo fixos os componentes como pH, concentração de cafeína e a potência da lâmpada UV. 
Para analisar os resultados obtidos nos experimentos foi verificada a degradação da cafeína, após os tratamentos com os POAs, utilizando espectrofotometria de absorção molecular e extração com clorofórmio para análise das concentrações.

\section{PADRÕES DE QUALIDADE E TRATAMENTO DA ÁGUA}

A Portaria do Ministério da Saúde $\mathrm{n}^{\mathrm{o}}$ 2.914, de 12 de dezembro de 2011, dispõe sobre os procedimentos de controle e de vigilância da qualidade da água para consumo humano e seu padrão de potabilidade. Os padrões de potabilidade da água estão divididos em biológicos, físico-químicos, substâncias inorgânicas e orgânicas, agrotóxicos, produtos secundários da desinfecção, cianotoxinas e substâncias radioativas.

Segundo o Guia de Potabilidade para Substâncias Químicas (UMBUZEIRO, 2012), pesquisas realizadas no estado de São Paulo apontam a presença ou presença potencial de substâncias químicas nos mananciais que não são contempladas na legislação nacional, mas que expõem a população via água potável, recreação e consumo de pescados e frutos do mar.

De acordo com Souza (2011), atualmente existe um grupo especial de substâncias de características peculiares, com níveis crescentes de uso que são chamados micropoluentes emergentes. Os compostos que entram neste grupo são fármacos, desreguladores endócrinos e de produtos de cuidado pessoal.

De acordo com Von Sperling (2005), os micropoluentes orgânicos são considerados compostos resistentes à degradação biológica, não integrando os ciclos biogeoquímicos, e acumulando-se em determinado ponto do ciclo. Nos contaminantes emergentes a avaliação da toxicidade existente ainda não permite o estabelecimento de doses de referência, ou seja, estabelecer critérios de qualidade quanto a eles (UMBUZEIRO, 2012).

Para o tratamento da água, a tecnologia de tratamento mais difundida no Brasil é denominada convencional e se baseia em diferentes fases: coagulação, floculação, decantação ou flotação, filtração (ascendente ou descendente), desinfecção, fluoretação e correção de pH (LIBÂNIO,2008).

Segundo Macêdo (2001), a qualidade final da água tratada depende das características do manancial, pois alguns compostos químicos tóxicos, dificilmente são removidos pelos tratamentos convencionais.

\subsection{Poluição por esgoto sanitário e os micropoluentes emergentes}

São crescentes os problemas de poluição dos recursos hídricos relacionados ao crescimento demográfico e ao despejo inadequado de esgoto em rios lagos e mares. Durante as últimas décadas, um elevado número de compostos orgânicos tem sido detectado nas águas superficiais (GONÇALVES, 2008). 
Muitos contaminantes despejados em corpos d'água estão relacionados aos diversos produtos de consumo humano como alimentos, medicamentos e bebidas. Tais contaminantes podem ser, por exemplo, compostos encontradas em medicamentos (tais como ácido acetilsalicílico - utilizado como analgésico e anti-inflamatório) que não são eliminados totalmente através dos processos usuais de tratamento de água e esgoto (GONÇALVES, 2008).

A contaminação do meio ambiente por medicamentos ocorre através da excreção sob forma de urina e fezes, e chegam por meio de esgotos sanitários, assim como esgotos industriais ou laboratoriais (SOUZA, 2011).

Anualmente, centenas de toneladas de produtos farmacêuticos são total ou parcialmente metabolizados, excretados pelo organismo e descartados no meio ambiente, tanto em sua forma original como na forma metabolizada. Vários estudos vêm relatando a presença de micropoluentes emergentes em níveis traço em diferentes partes do mundo, encontrados em esgoto sanitário, hospitalares, industriais, lixiviado, águas superficiais, ambientes marinhos e sedimentos (GONÇALVES, 2008).

Micropoluentes emergentes presentes nos esgotos sanitários exercem efeitos tóxicos sobre animais silvestres, como a desregulação endócrina, tendo o potencial de afetar adversamente a saúde humana, mesmo em concentrações da ordem de microgramas por litro $(\mu \mathrm{g} / \mathrm{L})$ ou nanogramas por litro $(\mathrm{ng} / \mathrm{L})$ (LEITE; AFONSO; AQUINO, 2010).

Souza (2011), cita alguns compostos considerados micropoluentes emergentes:

- Fármacos: trimetoprima, eritromicina, lincomicina, sulfametoxazol, cloranfenicol, amoxilina, ibuprofeno, diclofenaco, fenoprofeno, acetaminofeno, naproxeno, ácido acetilsalicílico, fluoxetina, cetoprofeno, indometacina, paracetamol, diazepam, carbamazepina, primidona, salbutamol, ácido clofíbrico, bezafibrato, ácido fenofibrico, etofibrato, gemfibrozil, metoprolol, propranolol, timolol, sotalol, atenolol, iopromida, iopamidol, diatrizoato.

- Produtos de Cuidado pessoal: nitro, perfumes policíclicos e macrocíclicos, ftalatos, benzofenona, cânfora, metilbenzilideno, N,Ndietiltoluamida, triclosan, clorofeno.

- Desreguladores endócrinos: alquilfenóis, ftalatos, bisfenol-A, estireno, retardantes de chama bromados (PBDEs), surfactantes (perfluoroctano sulfonados - PFOS), estradiol, estrona, estriol, dietilestilbestrol, PCF (pentaclorofenol), rifuralin, atrazina, DBCP (dibromocloropropano), lindano.

De acordo com Tubbs, Freire e Yoshinaga (2004), são incluídos os compostos como cafeína, colesterol e antioxidantes ao grupo dos micropoluentes de origem farmacêutica e produtos de cuidado pessoal, também chamados de PPCPs (Pharmaceuticals and Personal Care Products). 
A cafeína é um indicador potencial de contaminação por esgotos domésticos (SEILER et al., 1999) e enquadrada como fármaco, muito utilizada como estimulante cardíaco, cerebral e respiratório, além de possuir efeito diurético (GONÇALVES, 2008). A cafeína tem uma meia-vida de 30 dias em ambientes naturais, permitindo sua aplicação como indicador (GONÇALVES, 2008).

Apesar de uma pequena parte da população consumir cafeína na forma de fármacos, como por exemplo, antigripais, grande parte desta substância é ingerida na forma de bebidas (MARIA; MOREIRA, 2007).

Santana (2013) relata que no caso da cafeína, em baixas concentrações não possuem efeitos tóxicos (a não ser por exposição crônica), mas sim pode ser utilizada como indicador de poluição por esgoto e ser associada à ocorrência de outras substâncias no ambiente como diversos tipos de contaminantes emergentes, e até como indicadora da atividade estrogênica.

O Instituto Nacional de Ciências e Tecnologias Analíticas Avançadas (INCTAA) realizou em 2013 um levantamento nacional, coletando amostras de água em 20 capitais brasileiras, com o intuito de mapear a cafeína e outros contaminantes emergentes. Os resultados para a cafeína em água para consumo humano apresentaram os maiores valores em Porto Alegre, no estado do Rio Grande do Sul, com concentrações médias de 2257 ng/L.

\section{PROCESSOS OXIDATIVOS AVANÇADOS PARA DEGRADAÇÃO DE MICROPOLUENTES}

Segundo Baird, Recio e Carrera (2002), os processos oxidativos avançados visam mineralizar os poluentes, isto é, convertê-los inteiramente em $\mathrm{CO}_{2}, \mathrm{H}_{2} \mathrm{O}$ e ácidos minerais como $\mathrm{HCl}$, geralmente a temperatura ambiente.

Dentro das técnicas existentes se utilizam os processos fotoquímicos de oxidação como a radiação ultravioleta, que geram o radical hidroxila $(\bullet \mathrm{OH})$ que uma vez gerados são altamente reativos e pouco seletivos, podendo atuar na oxidação química de uma vasta gama de substâncias (MELO et al., 2009). Os radicais hidroxila atacam moléculas orgânicas pela abstração de um átomo de hidrogênio ou pela adição às duplas ligações (AMORIM; LEÃO; MOREIRA, 2009).

O mecanismo do POA segundo Teixeira e Jardim (2004), se dá pela formação de radicais hidroxila que apresentam o seu potencial redox $\left(\mathrm{E}^{0}\right)$ de $2,80 \mathrm{~V}$ a $25^{\circ} \mathrm{C}$, só ficando atrás do flúor que apresenta $\mathrm{E}^{0}=3,03 \mathrm{~V}$ a $25^{\circ} \mathrm{C}$.

Comumente, os processos fotoquímicos não degradam inteiramente os compostos, assim são associadas oxidantes como peróxido de hidrogênio e compostos de ferro (SOUZA, 2011). 
Os principais processos oxidativos avançados são a fotólise de peróxido de hidrogênio de peróxido de hidrogênio, ozonização, reagente Fenton, fotofenton e fotocatálise (GAMA, 2012).

De acordo com Melo et al. (2009), o Fenton é um dos processos conhecidos como oxidativos que utiliza peróxido de hidrogênio na presença de íons de $\mathrm{Fe}^{2+}$, em meio ácido. O Fenton apresenta uma simplicidade operacional, caráter homogêneo, e elevada eficiência de degradação, a qual pode ser ainda melhorada pela incorporação de radiação (ultravioleta ou visível), o que caracteriza os processos foto-fenton (DURIGAN; VAZ; ZAMORA, 2012).

$\mathrm{O}$ foto-fenton é um dos POAs que utiliza exposição à radiação UV, o reagente sulfato de ferroso heptahidratado e o peróxido de hidrogênio, em condições ácidas (NAPOLEÃO et al., 2011).

O processo foto-fenton possui as mesmas características do processo Fenton, mas com a vantagem da formação adicional de radicais hidroxila e íons $\mathrm{Fe}^{2+}$, ocorrida pela radiação UV. Os íons $\mathrm{Fe}^{2+}$ produzidos voltam a ser oxidados na reação de Fenton, formando um ciclo $\mathrm{Fe}^{+2} / \mathrm{Fe}^{+3}$, o que aumenta a extensão do processo oxidativo avançado (GAMA, 2012). Estes processos apresentam maior eficiência de degradação que os processos Fenton, devido à incorporação da radiação (DURIGAN, 2012).

$\mathrm{O}$ íons $\mathrm{Fe}^{2+} \mathrm{Fe}^{3+}$ catalisam os processos de Fenton e foto-fenton, pois formam hidróxidos insolúveis, influenciado pelo $\mathrm{pH}$ do meio que deve estar entre 2,5 e 3,0. Com pH acima de 3 ocorre a precipitação de $\mathrm{Fe}^{+3}$ interferindo na sua interação com peróxido de hidrogênio e na produção de $\bullet \mathrm{OH}$. Abaixo de $\mathrm{pH} 2,5$, apesar dos compostos de ferro não precipitarem, altas concentrações de $\mathrm{H}^{+}$podem sequestrar radicais hidroxila (NOGUEIRA et al., 2007).

De acordo com Gama (2012), o pH baixo faz com que ocorra a formação de aquocomplexos como o $\left[\mathrm{Fe}\left(\mathrm{H}_{2} \mathrm{O}\right)\right]^{+3}$, e em $\mathrm{pH}$ maior que 3 a espécie hidroxilada é majoritária. Devido a estas limitações de $\mathrm{pH}$ têm sido utilizados complexos orgânicos de ferro, como oxalatos e citratos.

Segundo Nogueira et al. (2007), o efeito prejudicial do excesso de peróxido de hidrogênio $\left(\mathrm{H}_{2} \mathrm{O}_{2}\right)$ na degradação de compostos orgânicos foi observado na degradação de herbicidas e efluentes, o que demanda uma atenção especial para a utilização da concentração adequada do componente. $\mathrm{O} \mathrm{H}_{2} \mathrm{O}_{2}$ pode atuar como sequestrador de radical hidroxila, formando o radical hidroperoxila $\left(\mathrm{HO}_{2}{ }^{\circ}\right)^{\prime}$ o qual apresenta um menor potencial de redução que - $\mathrm{OH}$, prejudicando o processo de degradação.

Conforme experimentos de Souza (2011) no processo oxidativo avançado fotólise de peróxido de hidrogênio, a cafeína obteve valores de $94,5 \%$ de remoção utilizando $200 \mathrm{mg} / \mathrm{L}$ de peróxido de hidrogênio, $\mathrm{pH} \mathrm{3,60} \mathrm{minutos}$ de contato e tempo de irradiação UV acima de 50 minutos.

Souza (2011) utilizou como fonte de radiação UV lâmpadas de vapor de mercúrio de baixa pressão com potência nominal de $15 \mathrm{~W}$, conhecidas como 
lâmpadas germicidas, em uma câmara de radiação constituída de um tubo de quartzo tubular.

Processos oxidativos avançados aplicados ao tratamento de águas podem apresentar eficiência de até $94 \%$ para remoção de fármacos (incluindo a cafeína) e perturbadores endócrinos e não geram resíduos no processo, mas podem apresentar subprodutos tóxicos na oxidação se a dosagem de oxidante, o pH e o tempo de contato não forem controlados (SASAKI, 2012).

\section{PLANEJAMENTO EXPERIMENTAL DO TIPO FATORIAL MULTIVARIADO}

Para uma melhor avaliação dos processos oxidativos avançados são utilizados sistemas de planejamento fatorial, que avaliam simultaneamente o efeito de diversas variáveis, a partir de um número reduzido de ensaios, verificando a influência de todas as variáveis experimentais e seus efeitos de interação. Quando a combinação de $k$ fatores é investigada em dois níveis, um planejamento fatorial consistirá de $2 k$ experimentos (SOUZA, 2011).

De acordo com Napoleão et al. (2011), diversos fatores influenciam o processo Fenton como $\mathrm{pH}$, temperatura, concentração de ferro (tipo de ferro), concentração de $\mathrm{H}_{2} \mathrm{O}_{2}$, tempo de reação, efeito dos radicais hidroxilas, por isso, o planejamento fatorial estuda a combinação dos fatores e verifica os que mais contribuem para uma maior eficiência.

\section{METODOLOGIA}

A metodologia empregada para extrair a cafeína da água é a extração com clorofórmio, baseado no método utilizado por Welter (2011) na determinação da cafeína em energéticos. Após a extração, foi realizada a análise da concentração da cafeína recuperada no espectrofotômetro de absorção molecular. O método espectrométrico foi escolhido devido ao seu menor custo e disponibilidade, além de apresentar resultados confiáveis.

Para analisar a cafeína no espectrofotômetro foi necessário fazer a curva de calibração para a cafeína em clorofórmio, utilizando soluções padrões preparadas. Para isso foram utilizados padrões de cafeína em diversas concentrações: $1,2,5,5,10,15,20$ e $25 \mathrm{mg} / \mathrm{L}$ de cafeína em clorofórmio e um branco com clorofórmio. O equipamento utilizado foi o espectrofotômetro de absorção molecular UV-Visível da Thermo Scientific, modelo Glos.

A leitura dos padrões foi realizada a $272 \mathrm{~nm}$, o comprimento de onda máximo para a absorção de radiação pela cafeína (WELTER, 2011).

O procedimento de extração da cafeína foi realizado a partir de uma solução estoque padrão de cafeína, com concentração conhecida, e preparada com água ultrapura, e com ela foi feita a análise de recuperação da cafeína. Com 
a curva previamente confeccionada foi verificada a concentração de cafeína comparando com a concentração inicial.

A extração da cafeína utilizada por Welter (2011) foi baseada na técnica utilizada para análise de cafeína em chás utilizada por Alves e Bragagnolo (2002). Para fins de otimização, foi realizada a extração com o solvente clorofórmio em um funil de separação utilizando $10 \mathrm{~mL}$ de solução padrão de cafeína de $10 \mathrm{mg} / \mathrm{L}$ e extrair com $10 \mathrm{~mL}$ do solvente. O sistema foi agitado e após foi retirada a parte inferior do funil para análise da concentração de cafeína no espectrofotômetro em comprimento de onda $272 \mathrm{~nm}$.

\subsection{Ensaios de tratamento com Processos Oxidativos Avançados}

Para realizar os ensaios dos POAs, foi preparada uma solução de cafeína baseada em concentrações utilizadas em experimentos de Trovó et al. (2013), mas com valor reduzido para concentração de $10 \mathrm{mg} / \mathrm{L}$, devido a metodologia de deteç̧ão por espectrofotometria, e o uso de padrões de 1 a $25 \mathrm{mg} / \mathrm{L}$ de cafeína para construção da curva já mencionada.

Os testes Fenton foram realizados nas seguintes condições: $0,6 \mathrm{mg} / \mathrm{L}$ de $\mathrm{Fe}^{+2}$ e $34 \mathrm{mg} / \mathrm{L}$ de peróxido de hidrogênio e 14,5 mg/L de $\mathrm{Fe}^{+2}$ e $680 \mathrm{mg} / \mathrm{L}$ de peróxido de hidrogênio de acordo com Trovó et al. (2013), mas sem a exposição a lâmpada UV. Os ensaios foram realizados em um béquer utilizando $130 \mathrm{~mL}$ da solução de cafeína de concentração $10 \mathrm{mg} / \mathrm{L}$.

Para os testes de fotólise de peróxido de hidrogênio de peróxido de hidrogênio e foto-fenton, foi aplicado o planejamento fatorial de $2^{3}$, variando a quantidade de peróxido de hidrogênio, a concentração de $\mathrm{Fe}^{+2}$ e o tempo de exposição à radiação UV em lâmpada de $15 \mathrm{~W}$ para os testes de fotólise de peróxido de hidrogênio e foto-fenton. Já para o teste de Fenton foram utilizadas duas situações de experimentos com concentrações de $\mathrm{Fe}^{+2}$ e peróxido de hidrogênio variadas.

Para adição de $\mathrm{Fe}^{+2}$ foi utilizada uma solução de $0,25 \mathrm{M}$ de sulfato ferroso heptahidratado e o peróxido de hidrogênio foi 30\% p/p (TROVÓ et al., 2013).

$\mathrm{O} \mathrm{pH}$ foi mantido em 3, ajustado com ácido sulfúrico $10 \%$ (LI; NANABOINA; ZHOU; KORSHIN, 2012) e o volume fixado em $130 \mathrm{~mL}$ para todos os testes, que é o volume do reator utilizado.

O planejamento fatorial realizado foi o $2^{3}$, isto é, foi composto por 8 experimentos diferentes codificados conforme Tabela 1, utilizando os limites inferior superior das variáveis empregadas. 
Tabela 1 - Transcrição dos experimentos do planejamento fatorial multivariado

\begin{tabular}{cccc}
\hline \multirow{2}{*}{ EXPERIMENTOS } & $\begin{array}{c}\mathbf{F e}^{+2} \\
(\mathbf{m g} / \mathbf{L})\end{array}$ & $\begin{array}{c}\mathbf{H}_{2} \mathbf{O}_{2} \\
(\mathbf{m g} / \mathbf{L})\end{array}$ & $\begin{array}{c}\text { Tempo exposição } \\
\text { UV (min) }\end{array}$ \\
\cline { 2 - 4 } & $\mathbf{1}$ & $\mathbf{2}$ & $\mathbf{3}$ \\
\hline $\mathbf{1}$ & 0,0 & 34 & 1 \\
$\mathbf{2}$ & 0,6 & 34 & 1 \\
$\mathbf{3}$ & 0,0 & 680 & 1 \\
$\mathbf{4}$ & 0,6 & 680 & 1 \\
$\mathbf{5}$ & 0,0 & 34 & 10 \\
$\mathbf{6}$ & 0,6 & 34 & 10 \\
$\mathbf{7}$ & 0,0 & 680 & 10 \\
$\mathbf{8}$ & 0,6 & 680 & 10 \\
\hline
\end{tabular}

Fonte: Do autor (2016).

Os ensaios que foram realizados com radiação UV foram feitos em reator específico (FIGURA 1), composto por duas lâmpadas UV de $15 \mathrm{~W}$ em um suporte cilíndrico fechado de policloreto de vinila (PVC), onde a água a ser tratada foi introduzida em um tubo de quartzo dentro do reator. As lâmpadas são conectadas a um reator que é ligado na energia da rede $220 \mathrm{~V}$ e o tubo de quartzo tem capacidade para tratar $130 \mathrm{~mL}$ de água.

Figura 1 - Reator para testes de bancada de processos oxidativos avançados

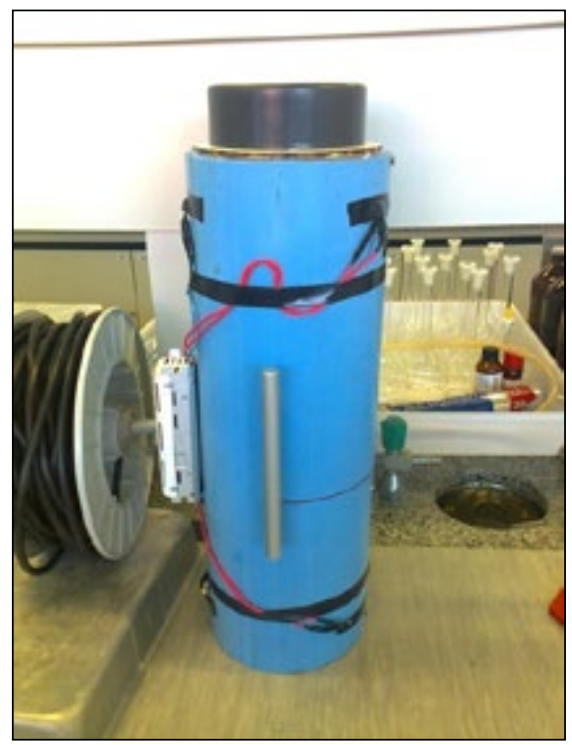

Fonte: Do autor (2016). 
A partir dos experimentos propostos pode-se analisar qual o processo oxidativo avançado mais eficaz para degradar totalmente a cafeína em amostras aquosas, visando o menor uso de produtos químicos e a menor exposição a radiação UV possível no caso dos processos de fotólise de peróxido de hidrogênio de peróxido de hidrogênio e foto-fenton.

\section{RESULTADOS E DISCUSSÕES}

A curva obtida no espectrofotômetro de absorção molecular (FIGURA 2), utilizando o comprimento de onda $272 \mathrm{~nm}$, e os padrões 1, 2,5, 5, 10, 15, 20, $25 \mathrm{mg} / \mathrm{L}$ de cafeína em clorofórmio diluídos a partir de uma solução estoque de $100 \mathrm{mg} / \mathrm{L}$, apresentou um coeficiente de correlação $\left(\mathrm{R}^{2}\right)$ de 0,9972 , próximo de 1 , o que indica uma boa linearidade.

Figura 2 - Curva da cafeína: concentração de Cafeína x Absorbância

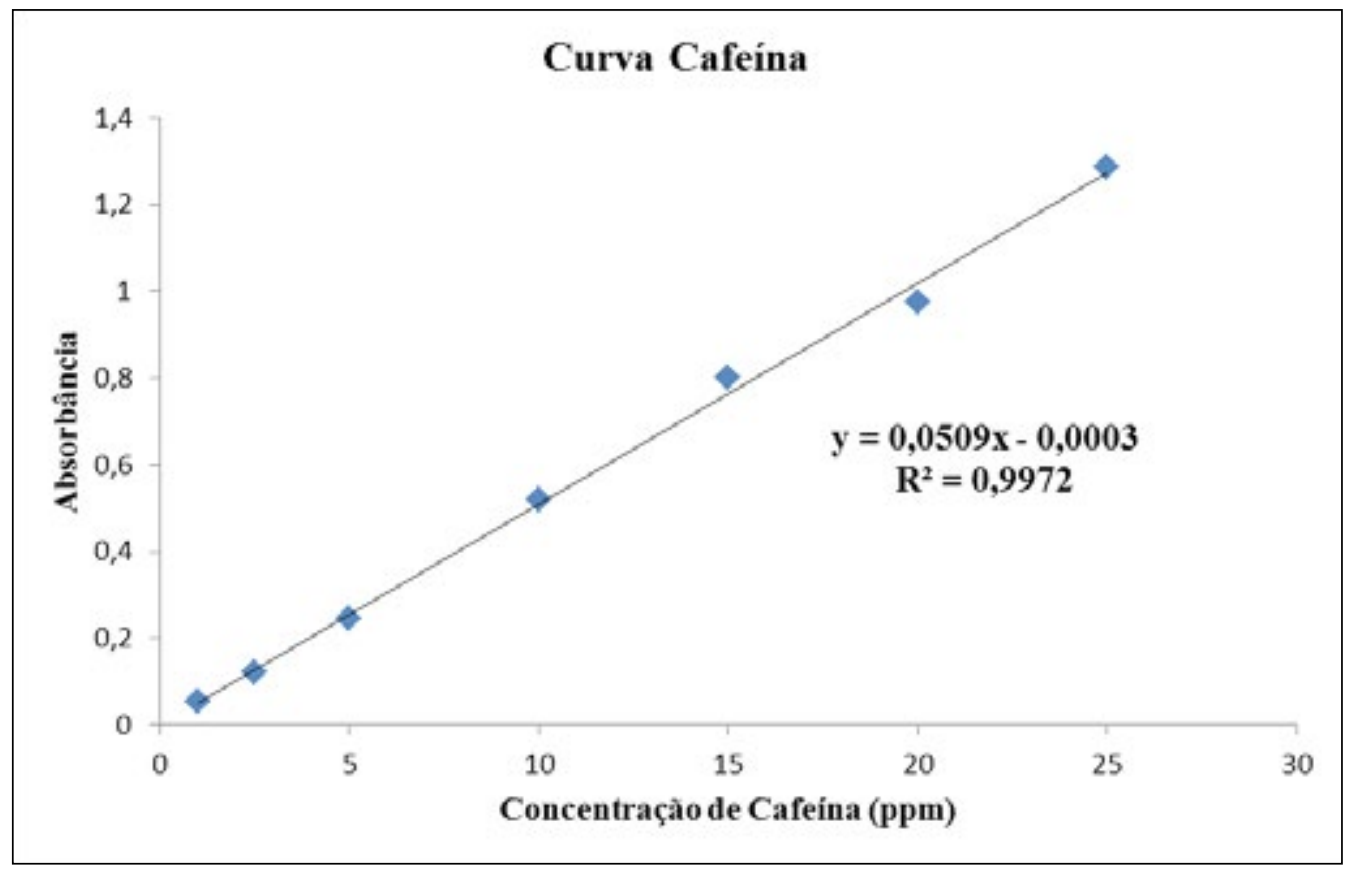

Fonte: Do autor (2016)

Com a curva obtida, foi realizado o teste de extração, utilizando 10 $\mathrm{mL}$ de solução padrão de $10 \mathrm{mg} / \mathrm{L}$ de cafeína em água e $10 \mathrm{~mL}$ de solvente clorofórmio em um funil de separação.

Depois de adicionado o solvente ao funil de separação, este foi submetido à agitação realizando a inversão 10 vezes para a completa homogeneização. $\mathrm{Na}$ parte inferior do funil fica a fase do clorofórmio com a cafeína extraída e na parte superior a água. 
Os testes resultaram positivamente a extração simples com solvente, tendo uma concentração inicial de $10 \mathrm{mg} / \mathrm{L}$ e extraída 9,58, 9,82 e 9,89 mg/L de cafeína, nos testes realizados em triplicata, tendo obtido uma margem de erro média de $2,5 \%$.

\section{Ensaios de tratamento utilizando os processos oxidativos avançados}

Os primeiros testes realizados foram com o processo Fenton, com a solução preparada de cafeína em água de concentração $10 \mathrm{mg} / \mathrm{L}$, utilizando um volume de $130 \mathrm{~mL}$ em um béquer. Os resultados obtidos foram:

Experimento A: 0,6 mg/L Fe ${ }^{+2}$ e $34 \mathrm{mg} / \mathrm{L}$ de peróxido de hidrogênio, foi obtida degradação de $80,8 \%$ da cafeína.

Experimento B: $14,5 \mathrm{mg} / \mathrm{L}$ de $\mathrm{Fe}^{+2}$ e $680 \mathrm{mg} / \mathrm{L}$ de peróxido de hidrogênio, foi obtida degradação de $78,3 \%$ da cafeína e apresentou coloração amarelada após a água ser submetida ao tratamento.

Os testes do POA Fenton não apresentaram resultados satisfatórios, pois apresentaram degradação de cafeína máxima de $80,8 \%$, assim partiu-se para os demais processos previstos com a radiação UV incluída no tratamento.

Para os ensaios de tratamento com processos oxidativos avançados com radiação UV, se projetou um reator para os ensaios de fotólise de peróxido de hidrogênio e foto-fenton e foram planejados 8 ensaios prévios para avaliar a fotólise de peróxido de hidrogênio e o foto-fenton, adicionando os itens $\mathrm{Fe}^{+2}$ e peróxido de hidrogênio e realizando a exposição ultravioleta dentro do reator conforme os tempos determinados.

Obteve-se os resultados expressos na Tabela 2, utilizando solução padrão de $10 \mathrm{mg} / \mathrm{L}$ de cafeína com $\mathrm{pH} 3$ e volume de $130 \mathrm{~mL}$.

Tabela 2 - Resultados do planejamento fatorial

\begin{tabular}{cccccc}
\hline \multirow{2}{*}{ EXPERIMENTOS } & $\begin{array}{c}\mathbf{F e}^{+2} \\
(\mathbf{m g} / \mathbf{L})\end{array}$ & $\begin{array}{c}\mathbf{H}_{2} \mathbf{O}_{2} \\
(\mathbf{m g} / \mathbf{L})\end{array}$ & $\begin{array}{c}\text { Tempo } \\
\text { exposição UV } \\
(\mathbf{m i n})\end{array}$ & $\begin{array}{c}\text { Concentração } \\
\text { cafeína (ppm) }\end{array}$ & $\begin{array}{c}\text { \% Redução } \\
\text { cafeína }\end{array}$ \\
\cline { 2 - 4 } & $\mathbf{1}$ & $\mathbf{2}$ & $\mathbf{3}$ & 3,29 & 67,1 \\
\hline 1 & 0,0 & 34 & 1 & 1,42 & 85,8 \\
3 & 0,6 & 34 & 1 & 6,00 & 40,0 \\
4 & 0,0 & 680 & 1 & 5,83 & 41,7 \\
5 & 0,6 & 680 & 1 & 0,54 & 94,6 \\
$\mathbf{6}$ & 0,0 & 34 & 10 & $\mathbf{0 , 3 1}$ & $\mathbf{9 6 , 9}$ \\
7 & $\mathbf{0 , 6}$ & $\mathbf{3 4}$ & $\mathbf{1 0}$ & 0,91 & 90,8 \\
8 & 0,0 & 680 & 10 & 0,56 & 94,4 \\
\hline
\end{tabular}

Fonte: Do autor (2016). 
De acordo com os resultados da Tabela 2, o melhor resultado foi do experimento 6 que se trata do POA foto-fenton, seguido do experimento 5 que se trata da fotólise de peróxido de hidrogênio. Observou-se que além dos resultados não serem satisfatório utilizando-se mais ferro, ainda se tem o residual do metal na água que a torna turva e com coloração amarelada.

Notou-se o efeito prejudicial do excesso de $\mathrm{H}_{2} \mathrm{O}_{2}$ na degradação da cafeína, onde $\mathrm{o}_{2} \mathrm{H}_{2}$ possivelmente atuou como sequestrador de radical hidroxila, formando o radical hidroperoxila $\left(\mathrm{HO}_{2} \bullet\right)$, e reduziu o potencial de redução do $\bullet \mathrm{OH}$, não apresentando a eficiência desejada.

A partir do experimento 5 , montou-se um novo planejamento fatorial $2^{3}$ para que os resultados de degradação da cafeína atingissem valores próximos a $100 \%$, então manteve-se os valores de 0,0 e $0,6 \mathrm{mg} / \mathrm{L}$ de $\mathrm{Fe}^{+2}, 34$ e $68 \mathrm{mg} / \mathrm{L}$ de peróxido de hidrogênio e tempos de exposição a radiação UV de 5 e 15 minutos. Os novos experimentos gerados seguem na Tabela 3, lembrando que a concentração inicial foi de $10 \mathrm{mg} / \mathrm{L}$ de cafeína e com ajuste de $\mathrm{pH}$ para 3.

Tabela 3 - Resultados do segundo planejamento fatorial $2^{3}$

\begin{tabular}{cccccc}
\hline \multirow{2}{*}{ EXPERIMENTOS } & $\begin{array}{c}\mathbf{F e}^{+2} \\
(\mathbf{m g} / \mathbf{L})\end{array}$ & $\begin{array}{c}\mathbf{H}_{2} \mathbf{O}_{2} \\
(\mathbf{m g} / \mathbf{L})\end{array}$ & $\begin{array}{c}\text { Tempo } \\
\text { exposição } \\
\text { (UV) }\end{array}$ & $\begin{array}{c}\text { Concentração } \\
\text { cafeína (ppm) }\end{array}$ & $\begin{array}{c}\text { \% Redução } \\
\text { cafeína }\end{array}$ \\
\cline { 2 - 4 } & $\mathbf{1}$ & $\mathbf{2}$ & $\mathbf{3}$ & & \\
\hline 1 & 0,0 & 34 & 5 & 0,26 & 97,4 \\
2 & 0,6 & 34 & 5 & 0,00 & 100 \\
$\mathbf{3}$ & $\mathbf{0 , 0}$ & $\mathbf{6 8}$ & $\mathbf{5}$ & $\mathbf{0 , 0 0}$ & $\mathbf{1 0 0}$ \\
4 & 0,6 & 68 & 5 & 0,00 & 100 \\
5 & 0,0 & 34 & 15 & 0,00 & 100 \\
6 & 0,6 & 34 & 15 & 0,60 & 94,0 \\
7 & 0,0 & 68 & 15 & 0,20 & 98,0 \\
8 & 0,6 & 68 & 15 & 0,00 & 100 \\
\hline
\end{tabular}

Fonte: Do autor (2016).

Dentre os resultados, muitos deles apresentaram 100\% de degradação da cafeína, ou seja, a cafeína foi totalmente mineralizada. O experimento 3 foi escolhido como a melhor condição, devido ao menor tempo de exposição a radiação UV e por não necessitar a adição do ferro para o tratamento, já que este produz alguns inconvenientes por deixar seu residual na água que deverá ser removido posteriormente. Sendo assim, a fotocatálise foi o processo oxidativo avançado que trouxe o melhor resultado em termos de degradação da cafeína. 


\section{CONSIDERAÇÕES FINAIS}

Após a realização dos 18 experimentos, aplicando processos de fotólise de peróxido e foto-fenton, foi possível verificar os melhores resultados para a degradação da cafeína. Assim, o processo oxidativo avançado de fotólise de peróxido de hidrogênio que se utilizou de $68 \mathrm{mg} / \mathrm{L}$ de peróxido de hidrogênio e tempo de exposição a lâmpada UV de 5 minutos obteve $100 \%$ de degradação da cafeína e foi considerado o tratamento mais adequado.

Cabe salientar que esse trabalho foi feito com o intuito de iniciar estudos de uma proposta de pós-tratamento convencional para a redução ou eliminação dos micropoluentes existentes nas águas e os valores de custos de cada teste ainda serão feitos.

\section{REFERÊNCIAS}

ALVES, Adriana Barreto; BRAGAGNOLO, Neura. Determinação simultânea de teobromina, teofilina e cafeína em chás por cromatografia líquida de alta eficiência. Revista Brasileira de Ciências Farmacêuticas. 2002. v. 38. ISSN 1516-9332.

AMORIM, Camila Costa de; LEÃO, Mônica Maria Diniz; MOREIRA, Regina de Fátima Peralta Muniz. Comparação entre diferentes processos oxidativos avançados para degradação de corante azo. Revista Engenharia Sanitária e Ambiental. 2009. v. 14. ISSN 1413-4152.

BAIRD, Colin; RECIO, Maria Angeles Lobo; CARRERA, Luiz Carlos Marques. Química ambiental. 2. ed. Porto Alegre: Bookman, 2002.

BRASIL, Ministério da saúde. Portaria 2.914, 2011. 5p. Disponível em: $<$ http:/ /bvsms. saude. gov.br/bvs/saudelegis/gm/2011/prt2914_12_12_2011.html> Acesso em: 20 de mar. 2016.

DALMÁZIO, Ilsa. Aplicação da espectrometria de massas com ionização electrospray no monitoramento de processo oxidativos avançados de interesse ambiental: degradação de fármacos, avaliação de sistemas oxidativos e oxidação do isopreno. 2007. Doutorado (Química Analítica). Universidade Federal de Minas Gerais, Belo Horizonte.

DURIGAN, Marco A. Benedetti; VAZ, Sergio Renato. ZAMORA, Patrício Peralta. Degradação de poluentes emergentes por processos Fenton e foto-fenton. Química nova. 2012. v. 35.

GAMA, Mariana Roberto. Processos Fenton como alternativa na remoção de interferentes endócrinos e outros micropoluentes ambientais. Revista Virtual de Química, v. 4. 2012. Disponível em:<http://www.uff.br/RVQ/index.php/rvq/ article/viewFile/299/283> Acesso em 2 de abr. 2016. 
GONÇALVES, Eline Simões. Uso da cafeína como indicador por esgoto doméstico em águas superficiais. 2008. Dissertação (mestrado em Geoquímica Ambiental). Universidade Federal Fluminense, Niterói.

LEITE, Gustavo de Souza; AFONSO, Robson José de Cássia Franco; AQUINO, Sérgio Francisco de. Caracterização de contaminantes presentes em sistemas de tratamento de esgotos, por cromatografia líquida acoplada à espectrometria de massas tandem em alta resolução. Química nova, v. 33, 2010. ISSN 0100-4042.

LI, W.; NANABOINA, V.; ZHOU, Q.; KORSHIN, G.V. Effects of Fenton treatment on the properties of effluent organic matter and their relationships with the degradation of pharmaceuticals and personal care products.2012. Disponível em: http:/ / www.ncbi.nlm.nih.gov/pubmed/22118906 Acesso em 23 de abr. 2016.

LIBÂNIO, Marcelo. Fundamentos de Qualidade e Tratamento de água.2. ed. São Paulo: Editora Átomo, 2008.

MACÊDO, Jorge Antônio Barros de. Águas \& Águas. São Paulo: Varela Editora e Livraria, 2001.

MARIA, Carlos A. B de; MOREIRA, Ricardo F. A. Cafeína: Revisão sobre métodos de análise. Química Nova, v. 30, 2007. ISSN 0100-4042.

MELO, Silene Alessandra Santos; TROVÓ, Alam Gustavo; BAUTITZ, Ivonete Rossi; NOGUEIRA, Raquel Fernandes Pupo. Degradação de fármacos residuais por processos oxidativos avançados. Química Nova, v. 32, 2009. ISSN 0100-4042.

NAPOLEÃO, Daniella Carla; SILVA, Rogério Ferreira da; SILVA, Paula Tereza de Souza e; BENACHOUR, Mohand; SILVA, Valdinete Lins da. Degradação de contaminante emergente (ácido acetilsalicílico) utilizando processo foto-fenton. 26 ${ }^{\circ}$ congresso brasileiro de engenharia sanitária e ambiental (2011). ABES - Associação Brasileira de Engenharia Sanitária e Ambiental.

NOGUEIRA, R.F.P.; TROVÓ, A.G.; SILVA, M.R.A.; VILLA, R.D. Fundamentos e aplicações ambientais dos processos Fenton e foto-fenton. Química Nova, v. 30, 2007. ISSN 0100-4042.

RICHTER, Carlos A.; NETTO, José M. de Azevedo. Tratamento de água. São Paulo: Editora Edgar Blücher Ltda, 1991.

SASAKI, Teresa Hatsue. O estado da arte da remoção de fármacos e perturbadores endócrinos em estações de tratamento de água (ETAs) e estações de tratamento de esgoto (ETEs). 2012. Monografia (Graduação em Engenharia Ambiental). Escola de Engenharia de São Carlos da Universidade de São Paulo, São Carlos.

SEILER Ralph L.; ZAUGG Steven D.; THOMAS, James. M; HOWCROFT, Darcy L. Caffeine and Pharmaceuticals as Indicators of Waste Water Contamination in Wells. GroundWater, 1999, v. 37. Disponível em:<http:/ /onlinelibrary.wiley.com/ doi/10.1111/j.1745-6584.1999.tb01118.x/abstract> Acesso em 23 de mar. 2016. 
SANTANA, Joyce da Silva. Determinação de contaminantes emergentes em mananciais de água bruta e na água para consumo humano do Distrito Federal. 2013. Mestrado. Pós-graduação em química. Universidade de Brasília, Brasília.

SOUZA, Neyliane Costa. Avaliação de Micropoluentes emergentes em esgoto e águas superficiais. 2011. Doutorado. Pós-graduação em Engenharia Civil - área de concentração saneamento ambiental. Universidade Federal do Ceará, Fortaleza.

TEIXEIRA, Cláudia Poli de Almeida Barêa; JARDIM, Wilson de Figueiredo. Processos oxidativos avançados: Conceitos teóricos. Caderno temático, v. 3. Universidade Estadual de Campinas, Instituto de Química, Laboratório de Química Ambiental. Campinas, 2004.

TROVÓ, Alam G. Silva, Tatiane F.S. GOMES JR., Oswaldo, MACHADO, Antônio E. H. NETO, Waldomiro Borges. MULLER JR., Paulo S., DANIEL, Daniela. Degradation of caffeine by photo-Fenton process: Optimization of treatment conditions using experimental design. Chemosphere, 2013. Disponível em:< http:/ / www.ncbi.nlm. nih.gov/pubmed/22795305> Acesso em 04 de mai. 2016.

TUBBS, Décio; FREIRE, Ronald Bastos; YOSHINAGA, Sueli. Utilização da Cafeína como indicador de contaminação das águas subterrâneas por esgotos domésticos no bairro de Piranema - Município de Seropédica e Itaguaí / RJ. XIII Congresso Brasileiro de águas subterrâneas, 2004.

UMBUZEIRO, Gisela de Aragão. Guia de Potabilidade para Substâncias Químicas. São Paulo: Editora Limiar, 2012.

VON SPERLING, Marcos. Introdução a qualidade das águas e ao tratamento de esgotos. 3. ed. Belo Horizonte: DESA/UFMG, 2005.

WELTER, Sinara Queli. Extração e Quantificação de cafeína em energéticos através da cromatografia líquida de alta eficiência e espectrofotometria. 2011. Monografia (Bacharel em Química). Universidade Tecnológica Federal do Paraná. Pato Branco, 2011. 